\title{
Phytochemicals and cancer
}

\author{
Ian T. Johnson \\ Institute of Food Research, Norwich Research Park, Colney, Norwich NR4 7UA, UK
}

\begin{abstract}
Epidemiological studies showing a protective effect of diets rich in fruits and vegetables against cancer have focused attention on the possibility that biologically-active plant secondary metabolites exert anti-carcinogenic activity. This huge group of compounds, now collectively termed 'phytochemicals', provides much of the flavour and colour of edible plants and the beverages derived from them. Many of these compounds also exert anti-carcinogenic effects in animal models of cancer, and much progress has been made in defining their many biological activities at the molecular level. Such mechanisms include the detoxification and enhanced excretion of carcinogens, the suppression of inflammatory processes such as cyclooxygenase- 2 expression, inhibition of mitosis and the induction of apoptosis at various stages in the progression and promotion of cancer. However, much of the research on phytochemicals has been conducted in vitro, with little regard to the bioavailability and metabolism of the compounds studied. Many phytochemicals present in plant foods are poorly absorbed by human subjects, and this fraction usually undergoes metabolism and rapid excretion. Some compounds that do exert anti-carcinogenic effects at realistic doses may contribute to the putative benefits of plant foods such as berries, brassica vegetables and tea, but further research with human subjects is required to fully confirm and quantify such benefits. Chemoprevention using pharmacological doses of isolated compounds, or the development of 'customised' vegetables, may prove valuable but such strategies require a full risk-benefit analysis based on a thorough understanding of the long-term biological effects of what are often surprisingly active compounds.
\end{abstract}

Phytochemicals: Anti-carcinogenic activity: Molecular effects: Chemoprevention

A review by the author and colleagues was published in 1994 (Johnson et al. 1994) that explored the potential anticarcinogenic effects of a range of biologically-active secondary plant metabolites commonly present in human diets, and tentatively considered whether such compounds, now commonly referred to collectively as "phytochemicals', might usefully be regarded as a new class of micronutrients. The interest in these compounds was stimulated partly by the work of pioneers in this field such as Wattenberg $(1975 a, b)$, who first demonstrated the principles of chemoprevention by plant constituents in animal models, and partly by the wealth of epidemiological evidence then emerging for protective effects of diets rich in fruits and vegetables against a variety of cancers (Block et al. 1992). A great deal of new evidence has become available in the last decade, and awareness of the importance of plant foods in the prevention of chronic disease in general has grown apace (Daviglus et al. 2005; Houston et al. 2005; He et al. 2006). The aim of the present paper is to review some important aspects of emerging knowledge about the anti-carcinogenic effects of plant secondary metabolites at the cellular and molecular levels, and to reappraise the overall importance of these compounds and their metabolites in human nutrition. To begin with, however, it will be useful to consider briefly the most recent epidemiological evidence for anticarcinogenic effects of fruits and vegetables.

\section{Cancer, plant foods and human diets}

Much of the earliest evidence for protective effects of fruits and vegetables against cancer was based on casecontrol studies. In an important review Block and colleagues (Block et al. 1992) summarised the available evidence and showed that after controlling for confounding factors, individuals in the lowest population quartile for fruit and vegetable intake experience about twice the risk of cancer compared with those in the highest quartile. 


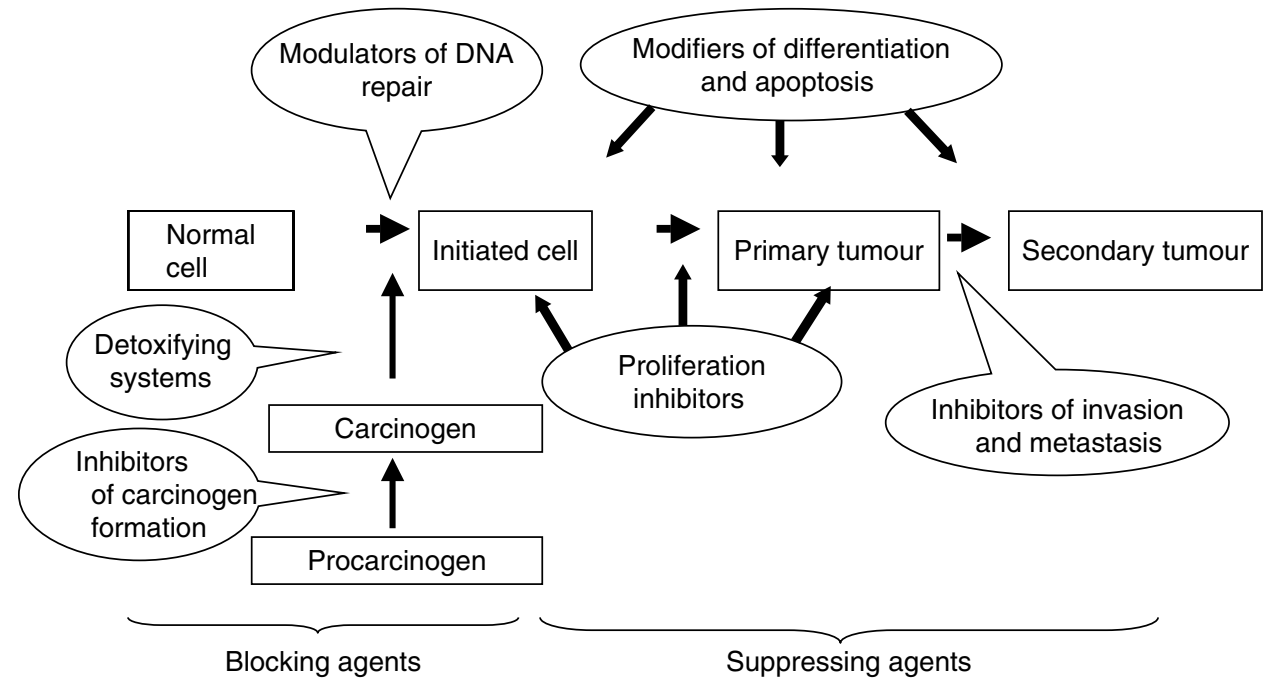

Fig. 1. A general scheme for interactions occurring between blocking agents and suppressing agents and the various stages in the sequence of events associated with the stepwise development of neoplasia. Blocking agents act immediately before or during the initiation of carcinogenesis by chemical carcinogens, and suppressing agents act after initiation, during the prolonged stages of promotion and progression. (Adapted from Johnson et al. 1994.)

A few years later Steinmetz \& Potter (1996) came to a similar conclusion, and the World Cancer Research Fund (1997) major study, Food, Nutrition and the Prevention of Cancer, found 'convincing' evidence for protective effects of fruits and vegetables against cancers of the upper aerophagic tract, stomach and lung, and of vegetables against cancers of the colon and rectum. Since the turn of the millennium, however, there appears to have been a shift in opinion toward the view that the evidence is less strong than originally thought, mainly because several large prospective studies focusing on the main causes of cancer in Western countries have found either no protective effects (Michels et al. 2000; Smith-Warner et al. 2001) or weaker effects than those expected on the basis of previous casecontrol studies (Terry et al. 2001; Smith-Warner et al. 2003). The recent publication of results on breast and prostate cancer derived from the European Prospective Investigation into Cancer and Nutrition (Key et al. 2004; van Gils et al. 2005) suggests that this trend is continuing.

The most comprehensive summary of the field currently available is probably that of the International Agency for Research on Cancer (2003), which has concluded that: 'There is limited evidence for a cancer-preventive effect of consumption of fruit and of vegetables for cancers of the mouth and pharynx, oesophagus, stomach, colon-rectum, larynx, lung, ovary (vegetables only), bladder (fruit only) and kidney. There is inadequate evidence for a cancerpreventive effect of consumption of fruit and vegetables for all other sites'. Nevertheless, although both the perceived size and statistical significance of the anticarcinogenic effects of diets rich in fruits and vegetables have diminished with the passage of time, interest in the biological effects of their constituents has grown. The emerging evidence for a variety of potentiallyimportant anti-carcinogenic mechanisms has stimulated interest in the broad concept of chemoprevention, focused attention on particular fruits and vegetables rich in the most active compounds and encouraged a more mechanistic approach to epidemiology. Some of these issues will be discussed after the molecular effects of particular groups of phytochemicals have been reviewed.

\section{Blocking tumour initiation}

Studies of the anti-carcinogenic effects of a variety of plants, plant constituents and synthetic chemopreventive agents led Wattenberg (1985) to define food-borne anticarcinogens generally as either blocking agents, which act immediately before or during the initiation of carcinogenesis by chemical carcinogens, or suppressing agents, which act after initiation during the prolonged stages of promotion and progression. This framework has been valuable for the development of research on the many different types of secondary plant metabolites that show biological activity in mammals (Johnson et al. 1994), and it continues to provide a valuable approach to the classification of these compounds and their effects. A scheme for the interactions between blocking agents, suppressing agents and the generalised sequence for the onset of neoplasia is shown in Fig. 1.

\section{Modulation of carcinogen metabolism}

Blocking agents prevent genotoxic carcinogens from forming adducts with DNA, either by inhibiting their activation from procarcinogens or by enhancing their detoxification and excretion. These actions are thought to be achieved primarily through the modulation of phase I and phase II metabolic enzymes in the gut, liver and other tissues exposed to the environment. Phase I metabolism involves the oxidation, reduction and hydrolysis of xenobiotics, including drugs, toxins and carcinogens, 
principally by the cytochrome P450 enzymes (Nelson et al. 1993). The products of phase I metabolism are often highly-reactive genotoxic intermediates that form substrates for phase II enzymes such as glutathione $S$-transferase (GST), NAD:quinone reductase and $\gamma$ glutamylcysteine synthetase, which then catalyse the formation of less-reactive water-soluble conjugates. These conjugates are then readily excreted via the kidneys or in bile. Certain anti-carcinogenic phytochemicals induce transcriptional activation of phase I and II enzymes, via the xenobiotic response element and the antioxidant response element respectively. The so-called monofunctional inducers are those that interact primarily with the antioxidant response element, and hence selectively induce phase II enzymes, without simultaneously inducing activation of carcinogens via increased phase I activity (Prochaska \& Talalay, 1988). The mechanism of induction is thought to be triggered by cellular stress, which leads to activation of intracellular protein kinases favouring the translocation of the transcription factor NF-E2 p45-related factor-2 to the nucleus, where it binds to the antioxidant response element and up regulates transcription (Itoh et al. 1997). Recent findings have shown that a second transcription factor, the aryl hydrocarbon receptor, interacts directly with the NF-E2 p45-related factor-2 promoter, and that this functional link contributes to the coupling of phase I and II enzymes as an integrated system (Miao et al. 2005).

Several groups of phytochemicals have now been identified as potent inducers of phase II enzymes; two of the most actively investigated are the flavanols, including epigallocatechin gallate, which is the principal biologically-active component of green tea (Chou et al. 2000), and the glucosinolate breakdown products, derived from cruciferous vegetables and herbs. Glucosinolates, of which $>100$ have been identified, are water-soluble glycosides containing a common $\mathrm{S}$ moiety and a variable side chain. They are found in cruciferous plants, a large and diverse group that contains mustard (Brassica juncea), rocket (Eruca sativa), radishes (Raphanus sativus) and the brassica vegetables (Mithen et al. 2000). Intact glucosinolates are biologically inactive and remain sequestered within cells throughout the plant. However, when the raw tissues are mechanically disrupted, the glucosinolates come into contact with the endogenous enzyme myrosinase and undergo hydrolysis, yielding an unstable intermediate that can give rise to a variety of active products (Mithen et al. 2000). Depending on the structure of the parent glucosinolate and the ambient conditions, these active products include isothiocyanates (ITC), nitriles, cyanoepithioalkanes and thiocyanates (Lambrix et al. 2001). In addition, the indolyl glucosinolates give rise to the indole-3-carbinols, which also induce detoxifying enzymes and act as anti-carcinogens in animal models (McDanell et al. 1988). Glucosinolate breakdown products can be formed in food processing, during digestion of uncooked vegetables in the upper gastrointestinal tract (Rouzaud et al. 2004) and by exposure to bacterial myrosinase in the colon (Rouzaud et al. 2003). Fig. 2 illustrates the release of glucosinolates in the gut lumen, the uptake and metabolism of the isothiocyanates and some possible sites of action and routes of excretion. The ITC sulforaphane, derived from broccoli (Brassica oleracea), acts via the NF-E2 p45related factor-2 pathway (McWalter et al. 2004) and is amongst the most active food-borne monofunctional inducers yet identified (Talalay \& Fahey, 2001).

A considerable amount of work has also been done to explore the importance of these effects at the whole organism level by studying carcinogen metabolism in animal models and in human subjects exposed to carcinogens from cigarette smoke. Both indole-3-carbinol and phenethyl ITC have been shown to modify the metabolism of the tobacco smoke carcinogen 4-(methylnitrosamino)-1-(3pyridyl)-1-butanone (NNK) in rodent models and inhibit the development of lung tumours, although their mechanisms of action differ. Indole-3-carbinol induces hepatic $\alpha$-hydroxylation of NNK, thus reducing the delivery of NNK to the lung (Morse et al. 1990), whereas phenethyl ITC inhibits $\alpha$-hydroxylation, and hence adduct formation in lung tissue (Hecht et al. 1996). The shunting of NNK metabolism away from the lung leads to increased hepatic metabolism and higher urinary excretion of NNK metabolites. Increased urinary excretion of two such metabolites, 4-(methylnitrosamino)-1-(3-pyridyl)-1butanol and [4-(methylnitrosamino)-1-(3-pyridyl)but-1yl]- $\beta$ - $\omega$-D-glucosiduronic acid in human smokers consuming approximately $170 \mathrm{~g}$ watercress (Rorippa nasturtium-aquaticum)/d for $3 \mathrm{~d}$ suggests that a similar mechanism occurs in human subjects (Hecht et al. 1995). Hecht and co-workers (Hecht et al. 2004) have recently conducted a study of NNK metabolites in Singapore Chinese smokers and have reported an inverse correlation between cruciferous vegetable consumption and excretion of NNK metabolites that appears consistent with the known metabolic effects of indole-3-carbinol. Overall, the experimental and epidemiological evidence supports the conclusion that glucosinolate breakdown products modulate phase II metabolism in man, although the contribution of this mechanism to the putative anticarcinogenic effects of cruciferous vegetable consumption remains to be fully established.

\section{Suppressing tumour progression}

Once the critical genetic damage has occurred, the next stages in the development of neoplasia are the acquisition of further mutations and epigenetic marks that cause progressively abnormal gene expression. This progression is the promotion stage of cancer development, characterised by poorly-regulated cell proliferation and differentiation, and a reduced tendency for damaged cells to undergo apoptosis. Eventually, the cancer phenotype emerges at one or more discrete sites. There are many stages at which this complex process might, in principle, be slowed or interrupted, and a correspondingly large number of plausible mechanisms for tumour suppression. Chemoprevention, the use of drugs or natural compounds at pharmacological levels to inhibit the development of cancer, is currently attracting a great deal of interest, particularly in the USA, but many of the same mechanisms may be triggered by phytochemicals occurring in substantial quantities in human diets. 


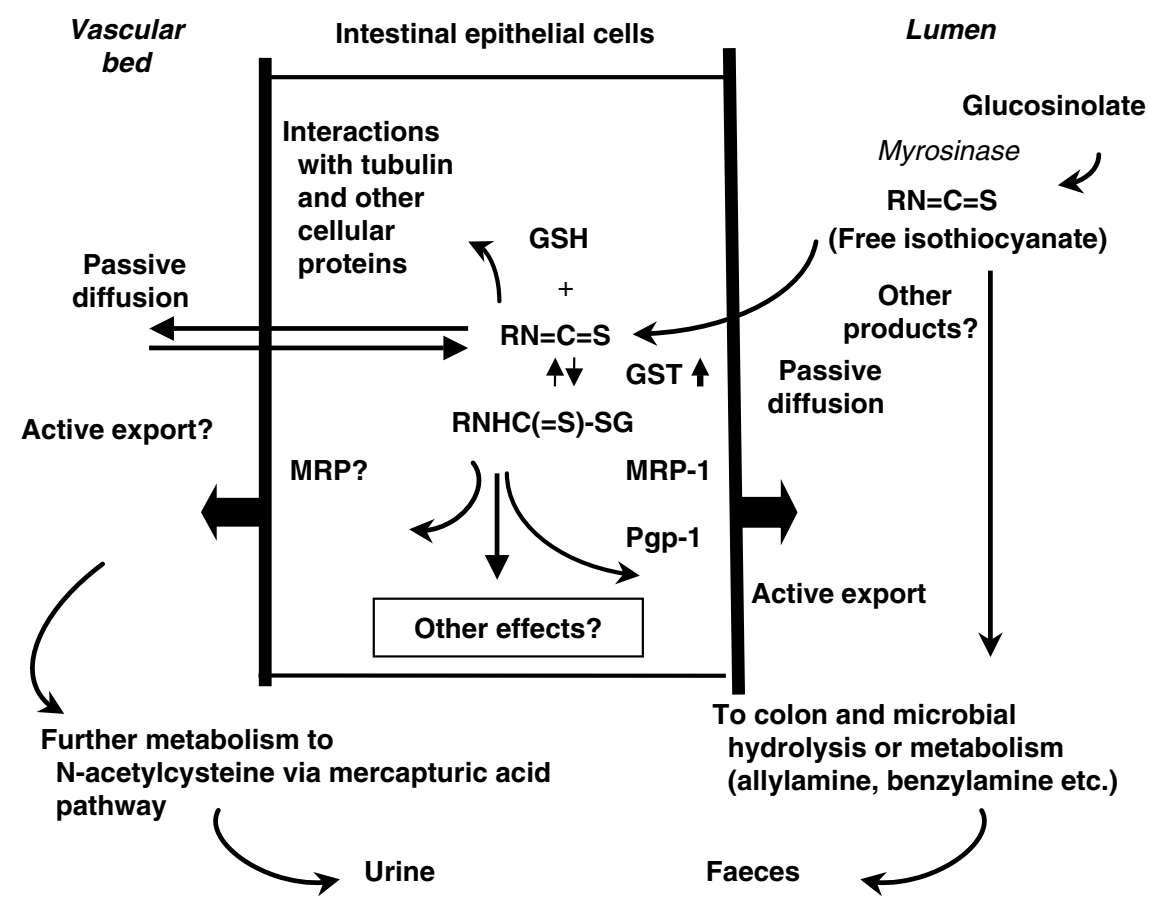

Fig. 2. Glucosinolates are broken down by myrosinase during food processing or during digestion, and isothiocyanates and other breakdown products are released into the lumen. Some remain unabsorbed and are eventually broken down by the gut microflora, but a substantial quantity of free isothiocyanates diffuse passively into the mucosal epithelial cells where they are rapidly conjugated with glutathione $(\mathrm{GSH})$, and then partially secreted back into the gut lumen by P-glycoprotein (Pgp-1) and multi-drug-resistance protein (MRP-1). Some free and conjugated isothiocyanates enter the bloodstream, however, and become available to interact with target tissues before further metabolism and urinary excretion. GST, glutathione $S$-transferase.

\section{Inflammation and cancer}

It has long been recognised that inflammation is a risk factor for certain cancers (Balkwill \& Mantovani, 2001). One obvious example is the increased risk of colo-rectal cancer associated with inflammatory bowel disease (Ekbom et al. 1990), but there are other examples of the involvement of inflammatory processes in the initiation and progress of cancer both within (Macarthur et al. 2004) and beyond the alimentary tract (Askling et al. 1999). There is also circumstantial evidence that chronic systemic inflammation, associated perhaps with the adverse metabolic factors now so common in prosperous Westernised societies (Johnson, 2005), may be a key driver for cancers of the alimentary tract (Helzlsouer et al. 2006). Furthermore, chronic use of aspirin and other anti-inflammatory drugs reduces the risk of cancers of the colon (Chan et al. 2005) and oesophagus (Vaughan et al. 2005). These various lines of evidence have focused attention on the molecular signals associated with inflammation, and on the phytochemicals that may modulate them.

$$
N F-\kappa B
$$

$\mathrm{NF}-\kappa \mathrm{B}$ is a collective term for a family of dimeric proteins that act as transcription factors. In its inactive form
$\mathrm{NF}-\kappa \mathrm{B}$ resides in the cytoplasm as a complex with the regulatory protein I $\mathrm{I} B$. The activation pathway for $N F-\kappa B$ involves phosphorylation, of I $\mathrm{KB}$ by I $\mathrm{B}$ kinase, leading to ubiquitination and proteolysis of IкB. This step frees NF- $\kappa B$ to translocate to the nucleus, where it binds to the $\mathrm{\kappa B}$ sequence motif in DNA and acts as a transcription factor for at least 200 genes involved in the regulation of inflammation, cell proliferation, differentiation and apoptosis. NF- $\mathrm{KB}$ is constitutively activated in many tumours, and its key role as an up-regulator of inflammation suggests that it plays a key role in the earliest stages of promotion and progression (Karin et al. 2002).

A host of phytochemicals, including resveratrol, limonene, glycyrrhizin, gingerol, indole-3-carbinol, genistein, apigenin and many others, have been shown to inhibit NF$\kappa \mathrm{B}$ activity at various different stages in its regulatory pathway. For example, curcumin, a widely-studied anticarcinogenic plant metabolite found in the spice cumin (Cuminum cyminum), suppresses TNF-induced activation of IкB kinase (Singh \& Aggarwal, 1995), whereas caffeic acid phenethyl ester specifically prevents binding of $\mathrm{NF}-\kappa \mathrm{B}$ to its target DNA sequence (Natarajan et al. 1996). The downstream effects of NF- $\kappa B$ inhibitors include reduced expression of the key pro-inflammatory enzymes inducible NO synthase and cyclooxygenase (COX)-2. 


\section{Cyclooxygenase inhibitors}

COX (PGH synthase) exists as two distinct isoforms; COX-1, which is constitutively expressed, produces PG essential to platelet aggregation and the maintenance of gastric mucosal integrity, whereas COX-2 is induced by tumour promoters and endogenous cytokines and produces PG involved in inflammatory processes. A third enzyme (COX-3) has been described that is a splice variant of $\mathrm{COX}-1$, and its physiological role in man is not yet clear. Both COX-1 and COX-2 are inhibited by aspirin, an acetylated derivative of the secondary plant metabolite salicylate, originally isolated from willow (Salix alba). Both aspirin and salicylate irreversibly inhibit the COX enzymes by selectively acetylating the hydroxyl group of a single serine residue, and they both also suppress NF- $\kappa B$ by inhibiting IKB kinase kinase activity (Yin et al. 1998). There is abundant evidence that a number of flavonoids are COX-2 enzyme inhibitors (Baumann et al. 1980) and some (e.g. apigenin, chrysin and kaempferol) can suppress $C O X$ 2 transcription by mechanisms including activation of the PPAR $\gamma$ transcription factor (Liang et al. 2001) and inhibition of NF- $\mathrm{KB}$ expression (Liang et al. 1999). Importantly, COX-2 transcription is inhibited in vitro not just by quercetin aglycone, but also by its human metabolites quercetin 3 -glucuronide, quercetin $3^{\prime}$-sulfate and $3^{\prime}$-methylquercetin 3 -glucuronide, and both quercetin and quercetin $3^{\prime}$-sulfate also inhibit COX-2 enzyme activity (O'Leary et al. 2004).

\section{Direct inhibition of mitosis: the Wnt signalling pathway}

The Wnt proteins are extracellular signalling molecules involved in the regulation of cell proliferation via the $\beta$ catenin signal pathway (Kundu et al. 2006). The nineteen known Wnt genes code for cysteine-rich glycoproteins; these proteins are released into the extracellular milieu where they modulate $\beta$-catenin signalling in target cells, via the membrane receptors Frizzled and LDL receptorrelated protein. The intracellular protein $\beta$-catenin regulates many aspects of cellular organisation, ranging from cytoskeletal structure to the regulation of cell proliferation and death (Wikramanayake et al. 2003). Levels of $\beta$-catenin in the cytoplasm are tightly regulated by a system of proteosomal degradation that begins when $\beta$-catenin forms a complex with the adenomatous polyposis coli protein and another scaffolding protein axin. This complex then associates with casein kinase I, which phosphorylates the $\mathrm{N}$ terminus of $\beta$-catenin, and glycogen synthase kinase $3 \beta$, which phosphorylates other $\beta$-catenin residues. The phosphorylated $\beta$-catenin molecule is then recognised by cytoplasmic $\beta$-transducin repeat-containing protein, which mediates its ubiquitination and degradation.

Wnt signalling plays an important role in gut formation during mammalian embyogenesis, and contributes to the maintenance of normal gut homeostasis in the adult. Disruption of Wnt signalling is a key abnormality during the development of cancers of the alimentary tract (Gregorieff $\&$ Clevers, 2005). In normal cells there is a relatively large and stable pool of inactive $\beta$-catenin associated with the cytoskeletal protein cadherin, and a small labile pool in the cytoplasm. However, in cancer cells the degradation pathway is often suppressed and the balance is altered in favour of the cytoplasmic pool. Active $\beta$-catenin migrates to the nucleus, where it activates the lymphoid enhancer factor/ $\mathrm{T}$-cell factor family of transcription factors (T-cell factors 1, 3 and 4, lymphoid enhancer factor), freeing them from repression by groucho and histone deacetylase, and leading to the transcription of a variety of effector genes including $C$-myc, cyclin-D1, c-jun and COX-2. It is well established that synthetic COX-2 inhibitors, including indomethacin and aspirin, suppress $\beta$-catenin/T-cell factor-mediated gene transcription in colo-rectal carcinoma cells (Dihlmann et al. 2001), and sulindac reduces nuclear $\beta$-catenin accumulation in the adenomatous polyps of patients with familial adenomatous polyposis (Boon et al. 2004). Moreover, a number of phytochemicals, including quercetin (Park et al. 2005), which suppresses colo-rectal crypt cell proliferation in the rat in vivo (Gee et al. 2002), also interact with the $\beta$-catenin pathway in vitro (Jaiswal et al. 2002; Joe et al. 2002). Dashwood et al. (2002) have shown that green tea, a minimally-processed 'white' tea and physiologically-relevant levels of epigallocatechin gallate all suppress nuclear $\beta$-catenin/T-cell factor 4 activity in HEK293 (kidney) cells in vitro. In the $A P C^{\text {min }}$ mouse model of colo-rectal cancer, in which the adenomatous polyposis coli protein is disabled by an $A P C$ mutation, treatment with white tea, green tea or the non-steroidal anti-inflammatory drug sulindac all suppress tumourigenesis (Orner et al. 2003). There was also evidence for suppression of $\beta$-catenin and its downstream products in the normal mucosa of mice treated with tea, and particularly in those treated with a combination of tea and sulindac.

\section{Induction of apoptosis}

Although the suppression of abnormal mitosis may slow the development of precancerous lesions and inhibit their competitive growth, the induction of programmed cell death can completely eliminate genetically-damaged cells from a tissue (Johnson, 2001). Several classes of phytochemicals, including organosulfur compounds (Xiao et al. 2005) from garlic (Allium sativum) and ITC, have been shown to induce apoptosis in cell lines. Although glucosinolate breakdown products act as powerful inducers of phase II enzymes and modulate carcinogen metabolism in vitro and in vivo, it is unlikely to be their only mode of action; there is also much interest in their ability to block mitosis and initiate apoptosis in a variety of epithelial cell lines and tissues. Oral administration of the pure glucosinolate sinigrin (Smith et al. 1998), the precursor of allyl ITC, or raw Brussels sprouts (Brassica oleracea var. gemmifera) rich in sinigrin (Smith et al. 2003) leads to an amplification of the apoptotic response occurring in colorectal crypts $48 \mathrm{~h}$ after exposure to the chemical carcinogen 1, 2 dimethylhydrazine. A high level of crypt-cell apoptosis is protective against colo-rectal neoplasia in both animal models (Chang et al. 1998) and human subjects (Martin et al. 2002). Importantly, the plasma and urinary metabolites to which the target tissues of human subjects are exposed in vivo may be just as effective as inducers of apoptosis as the parent ITC. Thus, the $N$-acetylcysteine conjugates of allyl ITC, benzyl ITC, phenethyl ITC and 
sulforaphane all readily inhibit proliferation and induce apoptosis in human bladder cancer cells (Tang et al. 2006). Furthermore, raw Brussels sprout juice exerts the same anti-proliferative effects as pure allyl ITC in vitro, yet contains no free allyl ITC (Smith et al. 2005). It is not entirely clear which of the other glucosinolate breakdown products and metabolites in raw Brussels sprout juice are responsible for this biological activity, but of those identified 1-cyano-2,3-epithiopropane, the gluconapin hydrolysis product, 3-butenyl isothiocyanate and the glucobrassicin metabolite ascorbigen are all candidates for this role. The mechanism of cell cycle arrest in vitro appears to involve a direct inhibition of tubulin polymerisation (Smith et al. 2004, 2005), but the involvement of this mechanism in the induction of apoptosis in vivo remains to be established.

\section{Molecular epidemiology}

One effect of the discovery that certain biologically-active constituents of plants exert anti-carcinogenic effects in model systems has been to focus the attention of epidemiologists on the particular fruits, vegetables and beverages that contain them. Interest in the area has also encouraged a more hypothesis-driven approach to epidemiology and the use of Mendelian randomisation to explore the effects of genetic polymorphisms on the consequences of particular dietary exposures (Davey Smith \& Ebrahim, 2005). Studies on cruciferous vegetables provide some of the best examples of this trend, although the results are still rather ambiguous.

As mentioned previously, the GST superfamily contains a group of phase II detoxifying enzymes that metabolise environmental chemicals including carcinogens, drugs and phytochemicals. Approximately half the individuals in most human populations are homozygous for the null alleles of GSTT1 and GSTM1, and hence cannot express some important components of GST activity. These genotypes appear to carry little increased risk of lung cancer, but Lin et al. (1998) have hypothesised that the GSTMI null condition might lead to a slower rate of metabolism of glucosinolate breakdown products. In high consumers of brassica vegetables this reduced rate of metabolism might be expected to enhance the exposure of target tissues to ITC, and hence confer greater protection against cancer. To test this hypothesis Lin et al. (1998) have conducted a case-control study of middle-aged patients undergoing screening sigmoidoscopy. A total of 459 cases having a first-time diagnosis of histologically-confirmed adenomas were compared with 507 controls with no polyp detected. Broccoli intake was assessed using a 126-item semiquantitative FFQ. Subjects with the highest quartile of broccoli intake ( 3.7 servings per week) had an OR of 0.47 (95\% CI $0.30,0.73$ ) for colo-rectal adenomas compared with subjects who ate no broccoli. When stratified by GSTM1 genotype this protective effect was observed only in patients null for GSTM1 $(P<0.001$ for trend; $P<0.01$ for interaction). However, Tijhuis et al. (2005) have conducted a similar study in The Netherlands and have reported increased risk of adenomatous polyps amongst high consumers of cruciferous vegetables, an effect that was shown to be amplified in those with a single nucleotide polymorphism in GSTP1 (OR 1.94 (95\% CI 1.02, 3.69)). No effects of the GSTT1 and GSTM1 deletion polymorphisms were observed. This unexpected finding might reflect differences in the population, the environment or the nature of the brassicas consumed, but it certainly deserves further investigation. Gasper et al. (2005) have suggested that some of the contradictory reports concerning the protective effects of cruciferous vegetables against cancers of the lung and other sites might reflect varietal differences in the vegetables consumed by oriental and Western populations.

Unlike colo-rectal cancer, most lung cancer can be clearly linked to well-defined environmental carcinogens. GST enzymes are involved in the metabolism of both tobacco-smoke carcinogens and glucosinolate breakdown products, and a number of studies have been focused on the possibility of interactions between GST polymorphisms and the putative protective effects of cruciferous vegetables. Spitz et al. (2000) have undertaken a case-control study in which patients newly-diagnosed with lung cancer and their controls were genotyped for GSTM1 and GSTT1, and have reported on consumption of crucifers by means of a semi-quantitative FFQ. Overall, lower intake of cruciferous vegetables was reported by the cases compared with the controls $(P=0 \cdot 009)$. Amongst current cigarette smokers a low intake of crucifers was found to carry an OR of $2 \cdot 22(95 \%$ CI $1 \cdot 2,4 \cdot 1)$ when combined with the GSTM1-null genotype and $3 \cdot 19$ (95\% CI 1.54, 6.62) when combined with the GSTT1-null genotype. In individuals carrying both null genotypes and consuming low levels of crucifers the OR rises to 5.45 (95\% CI 1.72, 17.22). In complete contrast to this finding, however, Zhao et al. (2001) have conducted a similar study amongst female patients with lung cancer and controls in Singapore and have shown stronger protective effects of cruciferous vegetable intake in individuals with null genotypes for GSTM1 and GSTT1. For example, in those null for both alleles and consuming higher levels of cruciferous vegetables, the OR is 0.47 (95\% CI $0 \cdot 23,0 \cdot 95$ ) compared with low consumers. Similar effects have been reported by London et al. (2000), working with another Chinese population in which exposure to cruciferous vegetables was determined objectively using urinary excretion of ITC metabolites as a biomarker, and more recently by Brennan et al. (2005), who have studied a central European population.

Generally speaking, phytochemicals are rather poorly absorbed by human subjects, and are themselves rapidly metabolised by the phase II enzymes. Much of this metabolism occurs in the gut mucosa (Fig. 2), and a large proportion of the resulting conjugates are actively secreted back into the gut lumen (Petri et al. 2003). A recent study of the uptake and metabolism of the ITC sulforaphane from broccoli by human volunteers (Gasper et al. 2005) has demonstrated that in comparison with GSTM1-positive individuals those who are GSTM1 null excrete a greater proportion of the consumed dose of sulforaphane via the urine. They consider various possible explanations for this observation, and tentatively propose that expression of GSTM1 leads to retention of sulforaphane at some systemic site or sites, which facilitates its anti-carcinogenic 
activity. An alternative explanation may be that in the GSTM1-null individuals the absence of GSTM1 expression reduces the efficiency with which the ITC is transported back into the gut lumen following absorption (Petri et al. 2003); however, further studies will be needed to resolve this issue.

\section{Conclusion}

Whatever the final assessment of the overall contribution of diets rich in fruits and vegetables to cancer prevention turns out to be, there is no doubt that the phytochemicals they contain do exert a range of fascinating and potentially-important biological effects on human cells. One obvious weakness of the current state of research, however, is that much of it has been conducted in vitro, with little regard for the bioavailability of the compounds studied. In most cases the small proportion of any compound that is absorbed undergoes extensive metabolism before reaching target organs, and the products are readily excreted. Although such phytochemicals cannot be regarded in any meaningful way as nutrients, their beneficial side effects may well be exploited in chemoprevention, much as those of drugs are, either by using pharmaceutical delivery systems, or through the development of 'customised' vegetables with high levels of selected phytochemicals (Mithen et al. 2003). Such strategies will, however, require a full risk-benefit analysis, based on a thorough understanding of their overall biological effects.

\section{Acknowledgements}

The author acknowledges financial support from the Biotechnology and Biological Sciences Research Council and the EU. Thanks go to Tracy Smith and Paul Kroon for useful comments on the manuscript.

\section{References}

Askling J, Grunewald J, Eklund A, Hillerdal G \& Ekbom A (1999) Increased risk for cancer following sarcoidosis. American Journal of Respiratory and Critical Care Medicine 160, 1668-1672.

Balkwill F \& Mantovani A (2001) Inflammation and cancer: back to Virchow? Lancet 357, 539-545.

Baumann J, von Bruchhausen F \& Wurm G (1980) Flavonoids and related compounds as inhibition of arachidonic acid peroxidation. Prostaglandins 20, 627-639.

Block G, Patterson B \& Subar A (1992) Fruit, vegetables, and cancer prevention: a review of the epidemiological evidence. Nutrition and Cancer 18, 1-29.

Boon EM, Keller JJ, Wormhoudt TA, Giardiello FM, Offerhaus GJ, van der Neut R \& Pals ST (2004) Sulindac targets nuclear beta-catenin accumulation and Wnt signalling in adenomas of patients with familial adenomatous polyposis and in human colo-rectal cancer cell lines. British Journal of Cancer 90, 224-229.

Brennan P, Hsu CC, Moullan N, Szeszenia-Dabrowska N, Lissowska J, Zaridze D et al. (2005) Effect of cruciferous vegetables on lung cancer in patients stratified by genetic status: a mendelian randomisation approach. Lancet $\mathbf{3 6 6}$, $1558-1560$.
Chan AT, Giovannucci EL, Meyerhardt JA, Schernhammer ES, Curhan GC \& Fuchs CS (2005) Long-term use of aspirin and nonsteroidal anti-inflammatory drugs and risk of colo-rectal cancer. Journal of the American Medical Association 294, 914-923.

Chang WL, Chapkin RS \& Lupton JR (1998) Fish oil blocks azoxymethane-induced rat colon tumorigenesis by increasing cell differentiation and apoptosis rather than decreasing cell proliferation. Journal of Nutrition 128, 491-497.

Chou FP, Chu YC, Hsu JD, Chiang HC \& Wang CJ (2000) Specific induction of glutathione S-transferase GSTM2 subunit expression by epigallocatechin gallate in rat liver. Biochemical Pharmacology 60, 643-650.

Dashwood WM, Orner GA \& Dashwood RH (2002) Inhibition of beta-catenin/Tcf activity by white tea, green tea, and epigallocatechin-3-gallate (EGCG): minor contribution of $\mathrm{H}(2) \mathrm{O}(2)$ at physiologically relevant EGCG concentrations. Biochemical and Biophysical Research Communications 296, 584-588.

Davey Smith G \& Ebrahim S (2005) What can mendelian randomisation tell us about modifiable behavioural and environmental exposures? British Medical Journal 330, 1076-1079.

Daviglus ML, Liu K, Pirzada A, Yan LL, Garside DB, Wang R et al. (2005) Relationship of fruit and vegetable consumption in middle-aged men to medicare expenditures in older age: the Chicago Western Electric Study. Journal of the American Dietetic Association 105, 1735-1744.

Dihlmann S, Siermann A \& von Knebel Doeberitz M (2001) The nonsteroidal anti-inflammatory drugs aspirin and indomethacin attenuate beta-catenin/TCF-4 signalling. Oncogene 20, 645-653.

Ekbom A, Helmick C, Zack M \& Adami HO (1990) Ulcerative colitis and colo-rectal cancer. A population-based study. New England Journal of Medicine 323, 1228-1233.

Gasper AV, Al-Janobi A, Smith JA, Bacon JR, Fortun P, Atherton C, Taylor MA, Hawkey CJ, Barrett DA \& Mithen RF (2005) Glutathione S-transferase M1 polymorphism and metabolism of sulforaphane from standard and high-glucosinolate broccoli. American Journal of Clinical Nutrition 82, 12831291.

Gee JM, Hara H \& Johnson IT (2002) Suppression of intestinal crypt cell proliferation and aberrant crypt foci by dietary quercetin in rats. Nutrition and Cancer 43, 193-201.

Gregorieff A \& Clevers H (2005) Wnt signaling in the intestinal epithelium: from endoderm to cancer. Genes and Development 19, 877-890.

He FJ, Nowson CA \& MacGregor GA (2006) Fruit and vegetable consumption and stroke: meta-analysis of cohort studies. Lancet 367, 320-326.

Hecht SS, Carmella SG, Kenney PM, Low SH, Arakawa K \& Yu MC (2004) Effects of cruciferous vegetable consumption on urinary metabolites of the tobacco-specific lung carcinogen 4-(methylnitrosamino)-1-(3-pyridyl)-1-butanone in Singapore Chinese. Cancer Epidemiology, Biomarkers and Prevention 13, 997-1004.

Hecht SS, Chung FL, Richie JP Jr, Akerkar SA, Borukhova A, Skowronski L \& Carmella SG (1995) Effects of watercress consumption on metabolism of a tobacco-specific lung carcinogen in smokers. Cancer Epidemiology, Biomarkers and Prevention 4, 877-884.

Hecht SS, Trushin N, Rigotty J, Carmella SG, Borukhova A, Akerkar S \& Rivenson A (1996) Complete inhibition of 4-(methylnitrosamino)-1-(3-pyridyl)-1-butanone-induced rat lung tumorigenesis and favorable modification of biomarkers by phenethyl isothiocyanate. Cancer Epidemiology, Biomarkers and Prevention 5, 645-652. 
Helzlsouer KJ, Erlinger TP \& Platz EA (2006) C-reactive protein levels and subsequent cancer outcomes: results from a prospective cohort study. European Journal of Cancer 42, 704-707.

Houston DK, Stevens J, Cai J \& Haines PS (2005) Dairy, fruit, and vegetable intakes and functional limitations and disability in a biracial cohort: the Atherosclerosis Risk in Communities Study. American Journal of Clinical Nutrition 81, 515-522.

International Agency for Research on Cancer (2003) Fruit and vegetables. Lyon, France: IARC Press.

Itoh K, Chiba T, Takahashi S, Ishii T, Igarashi K, Katoh Y et al. (1997) An Nrf2/small Maf heterodimer mediates the induction of phase II detoxifying enzyme genes through antioxidant response elements. Biochemical and Biophysical Research Communications 236, 313-322.

Jaiswal AS, Marlow BP, Gupta N \& Narayan S (2002) Betacatenin-mediated transactivation and cell-cell adhesion pathways are important in curcumin (diferuylmethane)-induced growth arrest and apoptosis in colon cancer cells. Oncogene 21, 8414-8427.

Joe AK, Liu H, Suzui M, Vural ME, Xiao D \& Weinstein IB (2002) Resveratrol induces growth inhibition, S-phase arrest, apoptosis, and changes in biomarker expression in several human cancer cell lines. Clinical Cancer Research 8, 893-903.

Johnson I, Williamson G \& Musk S (1994) Anticarcinogenic factors in plant foods: a new class of nutrients? Nutrition Research Reviews 7, 175-204.

Johnson IT (2001) Mechanisms and possible anticarcinogenic effects of diet related apoptosis in colo-rectal mucosa. Nutrition Research Reviews 14, 229-256.

Johnson IT (2005) Cancers of the gut and Western ills. Science 307, 1839.

Karin M, Cao Y, Greten FR \& Li ZW (2002) NF-kappaB in cancer: from innocent bystander to major culprit. Nature Reviews Cancer 2, 301-310.

Key TJ, Allen N, Appleby P, Overvad K, Tjonneland A, Miller A et al. (2004) Fruits and vegetables and prostate cancer: no association among 1104 cases in a prospective study of 130544 men in the European Prospective Investigation into Cancer and Nutrition (EPIC). International Journal of Cancer 109, 119-124.

Kundu JK, Choi K-Y \& Surh Y-J (2006) Beta-catenin-mediated sinalling: A novel molecular target for chemoprevention with anti-inflammatory substances. Biochimica et Biophysica Acta 1765, 14-24.

Lambrix V, Reichelt M, Mitchell-Olds T, Kliebenstein DJ \& Gershenzon J (2001) The Arabidopsis epithiospecifier protein promotes the hydrolysis of glucosinolates to nitriles and influences Trichoplusia ni herbivory. Plant Cell 13, 2793-2807.

Liang YC, Huang YT, Tsai SH, Lin-Shiau SY, Chen CF \& Lin JK (1999) Suppression of inducible cyclooxygenase and inducible nitric oxide synthase by apigenin and related flavonoids in mouse macrophages. Carcinogenesis 20, 1945-1952.

Liang YC, Tsai SH, Tsai DC, Lin-Shiau SY \& Lin JK (2001) Suppression of inducible cyclooxygenase and nitric oxide synthase through activation of peroxisome proliferatoractivated receptor-gamma by flavonoids in mouse macrophages. FEBS Letters 496, 12-18.

Lin HJ, Probst-Hensch NM, Louie AD, Kau IH, Witte JS, Ingles SA, Frankl HD, Lee ER \& Haile RW (1998) Glutathione transferase null genotype, broccoli, and lower prevalence of colo-rectal adenomas. Cancer Epidemiology, Biomarkers and Prevention 7, 647-652.

London SJ, Yuan JM, Chung FL, Gao YT, Coetzee GA, Ross RK \& Yu MC (2000) Isothiocyanates, glutathione S-transferase $\mathrm{M} 1$ and T1 polymorphisms, and lung-cancer risk: a prospective study of men in Shanghai, China. Lancet 356, 724-729.
McDanell R, McLean AE, Hanley AB, Heaney RK \& Fenwick GR (1988) Chemical and biological properties of indole glucosinolates (glucobrassicins): a review. Food and Chemical Toxicology 26, 59-70.

McWalter GK, Higgins LG, McLellan LI, Henderson CJ, Song L, Thornalley PJ, Itoh K, Yamamoto $\mathrm{M}$ \& Hayes JD (2004) Transcription factor Nrf2 is essential for induction of $\mathrm{NAD}(\mathrm{P}) \mathrm{H}$ :quinone oxidoreductase 1, glutathione S-transferases, and glutamate cysteine ligase by broccoli seeds and isothiocyanates. Journal of Nutrition 134, 3499S-3506S.

Macarthur M, Hold GL \& El-Omar EM (2004) Inflammation and cancer II. Role of chronic inflammation and cytokine gene polymorphisms in the pathogenesis of gastrointestinal malignancy. American Journal of Physiology 286, G515G520.

Martin C, Connelly A, Keku TO, Mountcastle SB, Galanko J, Woosley JT, Schliebe B, Lund PK \& Sandler RS (2002) Nonsteroidal anti-inflammatory drugs, apoptosis, and colorectal adenomas. Gastroenterology 123, 1770-1777.

Miao W, Hu L, Scrivens PJ \& Batist G (2005) Transcriptional regulation of NF-E2 p45-related factor (NRF2) expression by the aryl hydrocarbon receptor-xenobiotic response element signaling pathway: direct cross-talk between phase I and II drug-metabolizing enzymes. Journal of Biological Chemistry 280, 20340-20348.

Michels KB, Edward G, Joshipura KJ, Rosner BA, Stampfer MJ, Fuchs CS, Colditz GA, Speizer FE \& Willett WC (2000) Prospective study of fruit and vegetable consumption and incidence of colon and rectal cancers. Journal of the National Cancer Institute 92, 1740-1752.

Mithen R, Faulkner K, Magrath R, Rose P, Williamson G \& Marquez J (2003) Development of isothiocyanate-enriched broccoli, and its enhanced ability to induce phase 2 detoxification enzymes in mammalian cells. Theoretical and Applied Genetics 106, 727-734.

Mithen RF, Dekker M, Verkerk R, Rabot S \& Johnson IT (2000) The nutritional significance, biosynthesis and bioavailability of glucosinolates in human foods. Journal of the Science of Food and Agriculture 80, 967-984.

Morse MA, LaGreca SD, Amin SG \& Chung FL (1990) Effects of indole-3-carbinol on lung tumorigenesis and DNA methylation induced by 4-(methylnitrosamino)-1-(3-pyridyl)-1-butanone (NNK) and on the metabolism and disposition of NNK in A/J mice. Cancer Research 50, 2613-2617.

Natarajan K, Singh S, Burke TR Jr, Grunberger D \& Aggarwal BB (1996) Caffeic acid phenethyl ester is a potent and specific inhibitor of activation of nuclear transcription factor NF-kappa B. Proceedings of the National Academy of Sciences USA 93, 9090-9095.

Nelson DR, Kamataki T, Waxman DJ, Guengerich FP, Estabrook RW, Feyereisen R et al. (1993) The P450 superfamily: update on new sequences, gene mapping, accession numbers, early trivial names of enzymes, and nomenclature. DNA and Cell Biology 12, 1-51.

O'Leary KA, de Pascual-Tereasa S, Needs PW, Bao YP, O’Brien NM \& Williamson G (2004) Effect of flavonoids and vitamin $\mathrm{E}$ on cyclooxygenase-2 (COX-2) transcription. Mutation Research 551, 245-254.

Orner GA, Dashwood WM, Blum CA, Diaz GD, Li Q \& Dashwood RH (2003) Suppression of tumorigenesis in the Apc(min) mouse: down-regulation of beta-catenin signaling by a combination of tea plus sulindac. Carcinogenesis $\mathbf{2 4}$, 263-267.

Park CH, Chang JY, Hahm ER, Park S, Kim HK \& Yang CH (2005) Quercetin, a potent inhibitor against beta-catenin/Tcf signaling in SW480 colon cancer cells. Biochemical and Biophysical Research Communications 328, 227-234. 
Petri N, Tannergren C, Holst B, Mellon FA, Bao Y, Plumb GW et al. (2003) Absorption/metabolism of sulforaphane and quercetin, and regulation of phase II enzymes, in human jejunum in vivo. Drug Metabolism and Disposition 31, 805-813.

Prochaska HJ \& Talalay P (1988) Regulatory mechanisms of monofunctional and bifunctional anticarcinogenic enzyme inducers in murine liver. Cancer Research 48, 4776-4782.

Rouzaud G, Rabot S, Ratcliffe B \& Duncan AJ (2003) Influence of plant and bacterial myrosinase activity on the metabolic fate of glucosinolates in gnotobiotic rats. British Journal of Nutrition 90, 395-404.

Rouzaud G, Young SA \& Duncan AJ (2004) Hydrolysis of glucosinolates to isothiocyanates after ingestion of raw or microwaved cabbage by human volunteers. Cancer Epidemiology, Biomarkers and Prevention 13, 125-131.

Singh S \& Aggarwal BB (1995) Activation of transcription factor NF-kappa B is suppressed by curcumin (diferuloylmethane). Journal of Biological Chemistry 270, 24995-25000.

Smith TK, Lund EK, Clarke RG, Bennett RN \& Johnson IT (2005) Effects of Brussels sprout juice on the cell cycle and adhesion of human colo-rectal carcinoma cells (HT29) in vitro. Journal of Agricultural and Food Chemistry 53, 3895-3901.

Smith TK, Lund EK \& Johnson IT (1998) Inhibition of dimethylhydrazine-induced aberrant crypt foci and induction of apoptosis in rat colon following oral administration of the glucosinolate sinigrin. Carcinogenesis 19, 267-273.

Smith TK, Lund EK, Parker ML, Clarke RG \& Johnson IT (2004) Allyl-isothiocyanate causes mitotic block, loss of cell adhesion and disrupted cytoskeletal structure in HT29 cells. Carcinogenesis 25, 1409-1415.

Smith TK, Mithen R \& Johnson IT (2003) Effects of Brassica vegetable juice on the induction of apoptosis and aberrant crypt foci in rat colonic mucosal crypts in vivo. Carcinogenesis $\mathbf{2 4}$, 491-495.

Smith-Warner SA, Spiegelman D, Yaun SS, Adami HO, Beeson WL, van den Brandt PA et al. (2001) Intake of fruits and vegetables and risk of breast cancer: a pooled analysis of cohort studies. Journal of the American Medical Association 285, 769-776.

Smith-Warner SA, Spiegelman D, Yaun SS, Albanes D, Beeson WL, van den Brandt PA et al. (2003) Fruits, vegetables and lung cancer: a pooled analysis of cohort studies. International Journal of Cancer 107, 1001-1011.

Spitz MR, Duphorne CM, Detry MA, Pillow PC, Amos CI, Lei L, de Andrade M, Gu X, Hong WK \& Wu X (2000) Dietary intake of isothiocyanates: evidence of a joint effect with glutathione S-transferase polymorphisms in lung cancer risk. Cancer Epidemiology, Biomarkers and Prevention 9, 10171020.

Steinmetz KA \& Potter JD (1996) Vegetables, fruit, and cancer prevention: a review. Journal of the American Dietetic Association 96, 1027-1039.
Talalay P \& Fahey JW (2001) Phytochemicals from cruciferous plants protect against cancer by modulating carcinogen metabolism. Journal of Nutrition 131, 3027S-3033S.

Tang L, Li G, Song L \& Zhang Y (2006) The principal urinary metabolites of dietary isothiocyanates, $\mathrm{N}$-acetylcysteine conjugates, elicit the same anti-proliferative response as their parent compounds in human bladder cancer cells. Anticancer Drugs 17, 297-305.

Terry P, Terry JB \& Wolk A (2001) Fruit and vegetable consumption in the prevention of cancer: an update. Journal of Internal Medicine 250, 280-290.

Tijhuis MJ, Wark PA, Aarts JM, Visker MH, Nagengast FM, Kok FJ \& Kampman E (2005) GSTP1 and GSTA1 polymorphisms interact with cruciferous vegetable intake in colo-rectal adenoma risk. Cancer Epidemiology, Biomarkers and Prevention 14, 2943-2951.

van Gils $\mathrm{CH}$, Peeters PH, Bueno-de-Mesquita HB, Boshuizen HC, Lahmann PH, Clavel-Chapelon F et al. (2005) Consumption of vegetables and fruits and risk of breast cancer. Journal of the American Medical Association 293, 183-193.

Vaughan TL, Dong LM, Blount PL, Ayub K, Odze RD, Sanchez CA, Rabinovitch PS \& Reid BJ (2005) Non-steroidal antiinflammatory drugs and risk of neoplastic progression in Barrett's oesophagus: a prospective study. Lancet Oncology 6, 945-952.

Wattenberg LW (1975a) Effects of dietary constituents on the metabolism of chemical carcinogens. Cancer Research 35, 3326-3331.

Wattenberg LW (1975b) Inhibition of dimethylhydrazine-induced neoplasia of the large intestine by disulfiram. Journal of the National Cancer Institute 54, 1005-1006.

Wattenberg LW (1985) Chemoprevention of cancer. Cancer Research 45, 1-8.

Wikramanayake AH, Hong M, Lee PN, Pang K, Byrum CA, Bince JM, Xu R \& Martindale MQ (2003) An ancient role for nuclear beta-catenin in the evolution of axial polarity and germ layer segregation. Nature 426, 446-450.

World Cancer Research Fund (1997) Food, Nutrition and the Prevention of Cancer: A Global Perspective, pp. 216-251. Washington, DC: American Institute for Cancer Research.

Xiao D, Pinto JT, Gundersen GG \& Weinstein IB (2005) Effects of a series of organosulfur compounds on mitotic arrest and induction of apoptosis in colon cancer cells. Molecular Cancer Therapeutics 4, 1388-1398.

Yin MJ, Yamamoto Y \& Gaynor RB (1998) The anti-inflammatory agents aspirin and salicylate inhibit the activity of I(kappa)B kinase-beta. Nature 396, 77-80.

Zhao B, Seow A, Lee EJ, Poh WT, Teh M, Eng P, Wang YT, Tan WC, Yu MC \& Lee HP (2001) Dietary isothiocyanates, glutathione S-transferase-M1, -T1 polymorphisms and lung cancer risk among Chinese women in Singapore. Cancer Epidemiology, Biomarkers and Prevention 10, 1063-1067. 